\title{
Latent extinction as a function of partial reinforcement of the running response'
}

\author{
JAMES A. DYAL \\ TEXAS CHRISTIAN UNIVERSITY
}

\begin{abstract}
Three groups of rats were trained in a straight alley under either 80 reinforced and no non-reinforced trials (Group 80/0), 40 reinforced and 40 nonreinforced trials (Group 40/40), or 80 reinforced and 80 non-reinforced trials (Group 80/80). The groups were then given nonrewarded placement into either the goal box or a neutral box. It was found that PRE holds for latent extinction as well as regular extinction. Problem

One of the most reliable observations in the experimental study of animal learning is that intermittent reinforcement during acquisition results in an increased resistance to extinction when compared with the continuous reinforcement condition. The partial reinforcement extinction effect (PRE) is typically indexed by the number of trials to reach an arbitrary performance criterion during regular extinction, or by differential latencies following several extinction trials. It was the purpose of the present experiment to determine if the PRE holds in the case of latent or non-response extinction.
\end{abstract}

\section{Method}

The Ss were 56 male albino rats of the SpragueDawley strain 80-90 days old at the start of the experiment. The apparatus was the basic straight runway described in Dyal (1964).

Following adaptation to a 23-hr. food deprivation schedule and adaptation to the apparatus, the Ss were trained for 20 days in the straight alley runway. They were randomly assigned to three training groups. Group 80/0 received a total of 80 trials (four per day) all of which were reinforced by approximately $15 \mathrm{sec}$. of eating in the goal box. Group 40/40 received 80 training trials half of which were reinforced. The order of the reinforced vs non-reinforced trials was counterbalanced within blocks of 20 trials. Group 80/80 received 160 training trials (eight trials per day) again on a $50 \%$ reinforcement schedule. Within each training group Ss were also assigned to an experimental or control subgroup for the application of the latent extinction treatment. On Day 21, the Ss in each experimental subgroup were given five non-reinforced placements into the goal box. The Ss in the control group were given five placements into a 'neutral' box which differed from the goal box in color, shape, and extramaze cues. All placements were of a $60 \mathrm{sec}$. duration with a $60 \mathrm{sec}$. intertrial interval. Sixty to $90 \mathrm{sec}$. following the last placement each $\mathrm{S}$ was given the first regular extinction trial by being placed into the start box and permitted to traverse the runway into the unbaited goal box. Each $\mathrm{S}$ was then given 14 more extinction trials with an intertrial interval of $5 \mathrm{~min}$.

\section{Results and Discussion}

The mean start time and mean goal time during acquisition trials 41-80 were computed for each $\mathrm{S}$. Simple analysis of variance applied to these data indicated no significant difference among the groups in either start or goal times. Inspection of the running time data indicated that the group differences were quite small, similar to ST and GT, and thus no further analysis was undertaken.

Performance on the first trial is the most direct measure of the effects of latent extinction placements. Previous experiments (Dyal, 1962, 1964) had indicated that the most sensitive variable was goal time (GT), thus, most of the analyses were based on this measure.

In order to determine if the performance on the first test trial following placement was slower than comparable trials at the end of training, correlated t-tests were applied to compare the mean GT of training trial 1 on Days 19 and 20 and the GT on the first extinction trial (test trial 1). The results indicated that experimental groups $80 / 0$ and $80 / 80$ slowed down significantly in entering the goal box on test trial 1 $(p<.025$ and $<.05$ respectively). No other comparisons approached significance.

In the light of the robust character of the $\mathrm{F}$ statistic it was considered desirable to perform analysis of variance on the transformed goal times (log $1+$ GT) on test trial 1 despite highly significant heterogeneity of variance. The results indicated significant effects associated with training schedule, with experimental vs control, and with the interaction. In addition, because of the heterogeneity of variance a Kruskal-Wallis $\mathrm{H}-$ test was applied to the raw score data for all six groups (both factors combined). The resulting $\mathrm{H}$-value was $12.52(p<.10) . H$-test analysis of the experimental groups alone indicated a significant difference among the groups $(H=10.22, p<.01)$, while a comparable analysis of the control groups yielded no significant effect. Single group comparisons by means of MannWhitney U-tests revealed that experimental group 80/0 slowed down in entering the goal box on test trial 1 significantly more than all other groups (all $\mathrm{p}$ values .005 or less). No other group differences were significant.

The mean GT during regular extinction is represented in Fig. 1. Bartlett's test applied to the mean GT for trials 2-15 indicated the sample variance to be highly 


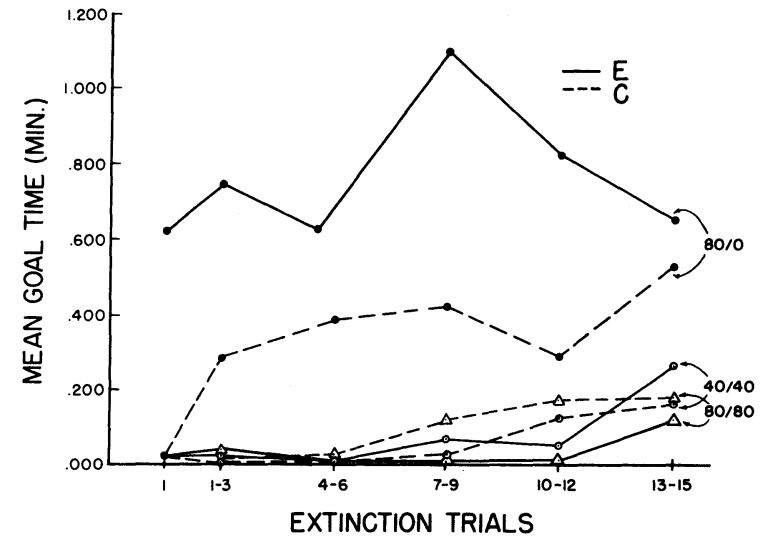

Fig. 1. Mean goal time during regular extinction and on test trial 1.

heterogenious; therefore, analysis of the data was based on a Kruskal-Wallis H-test. Comparison of all groups resulted in an $\mathrm{H}$-value of 28.93 which is significant beyond the .01 level. Individual group comparisons by $\mathrm{U}$-tests indicated that experimental group $80 / 0$ and control groups $80 / 0$ ran more slowly than all other groups ( $p<.001$ in all comparisons). No other subgroup comparisons were significant.
The effects of partial reinforcement on latent extinction are consistent with the PRE for regular extinction. The effectiveness of non-reinforced placement into the goal box just prior to regular extinction is considerably reduced if the Ss have been trained under partial reinforcement conditions. These results are consistent with those obtained by Wilson \& Dyal (1963) who found that those Ss which had received nonrewarded direct placements during training showed the least reduction in test-trial-1 goal speeds.

\section{Referenees}

Dyal, J. A. Latent extinction as a function of number and duration of pre-extinction exposures. J. exp. Psychol., 1962, 63, 98-104.

Dyal, J. A. Latent extinction as a function of number of training trials. Psychol. Rec., 1963, 13, 407-414.

Dyal, J. A. Latent extinction as a function of placement-test interval and irrelevant drive. J. exp. Psychol., 1964, 68, 486-491. Wilson, W. J., \& Dyal, J. A. Effects of nonresponse acquisition on latent extinction in a differential reinforcement setting. Psychol. Rep., 1963, 13, 879-884.

\section{Note}

1. This research was supported by Grant M-3331 from the National Institute of Mental Health. The data were collected by Mr. Richard Carpenter and Miss Judith Abright. Mr. Wayne J. Wilson performed the data analysis. 